This document is the Accepted Manuscript version of a Published Work that appeared in final form in Environmental Science and Technology, copyright @ American Chemical Society after peer

review and technical editing by the publisher. To access the final edited and published work see

\title{
CuH-ZSM-5 as Hydrocarbon Trap under cold start
}

\section{conditions}

\author{
M. Navlani-García ${ }^{a}$, B. Puértolas ${ }^{b}$, D. Lozano-Castello ${ }^{a,{ }^{*}}{ }^{*}$, D. Cazorla-Amorós $^{a}$, M. V. Navarro ${ }^{b}, T$. \\ García $^{b}$ \\ ${ }^{a}$ Instituto Universitario de Materiales, Departamento de Química Inorgánica, Universidad de Alicante. \\ Apartado 99, E-03080, Alicante, Spain, phone number: +34 965903 966, \\ FAX number: +34965903454 \\ b Instituto de Carboquímica (ICB-CSIC), M Luesma Castán 4, 50015-Zaragoza, Spain, phone number: \\ +34976733 977, FAX number: +34976733 318
}

\begin{abstract}
Cold start tests are carried out to evaluate the performance of copper-exchanged zeolites as hydrocarbon traps under simulated gasoline car exhaust gases, paying special attention to the role of copper in the performance of these zeolites. It is concluded that the partial substitution of the protons in the parent $\mathrm{H}$ ZSM-5 zeolite is highly beneficial for the hydrocarbon trapping due to the formation of selective adsorption sites with specific affinity for the different exhaust components. However, it is also observed that uncontrolled exchanging process conditions could lead to the presence of $\mathrm{CuO}$ nanoparticles in the zeolite surface, which seems to block the pore structure of the zeolite, decreasing the hydrocarbon trap efficiency. Among all the zeolites studied, the results point out that a CuH-ZSM-5 with a partial substitution of extra-framework proton by copper cations and without any detectable surface $\mathrm{CuO}$ nanoparticles, is the zeolite that showed the best performance under simulated cold start conditions due to both the high stability and the hydrocarbon retaining capacity of this sample during the consecutive
\end{abstract}


cycles.

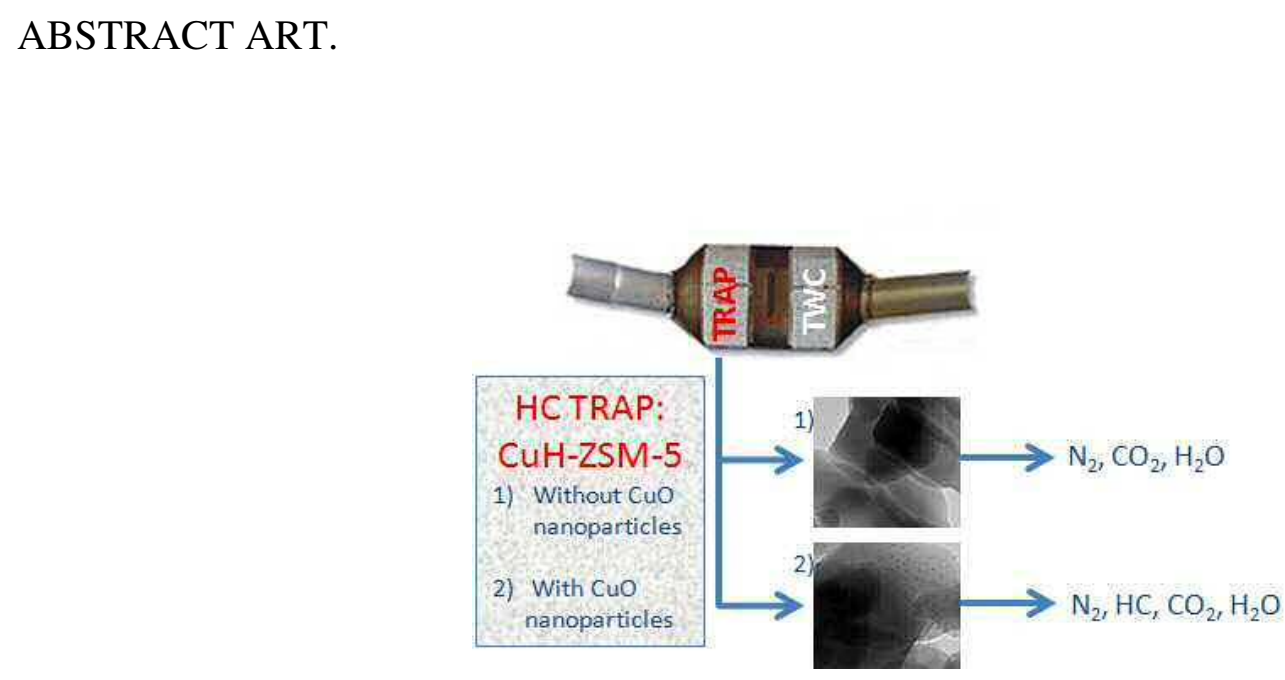

\section{Introduction}

During the past years, a significant effort has been made in order to reduce the hydrocarbon $(\mathrm{HC})$ emissions from internal combustion engines in gasoline vehicles during the cold start period. During this period, which accomplishes the first two minutes of operation, $50-80 \%$ of the total HC emissions are produced. Different solutions have been proposed to reduce these emissions, including both catalytic and some unique system approaches: ${ }^{1}$ close-coupled catalysts, electrically heated catalyzed metal monoliths, chemically heated catalysts, exhaust gas ignition, pre-heated burners, HC traps, etc. The use of $\mathrm{HC}$ traps before the three way catalyst (TWC) is a highly promising way to resolve this $\mathrm{HC}$ emission problem because this alternative presents interesting advantages like high efficiency, low cost, easy technical operation and less spatial and energy requirements ${ }^{1}$. Thus, many efforts have been focused on finding an ideal adsorbent for this application. Ideal $\mathrm{HC}$ traps must be able to adsorb and to retain $\mathrm{HCs}$ until the catalyst reaches the light-off temperature (around 200 to $300{ }^{\circ} \mathrm{C}$ ). At this point, $\mathrm{HCs}$ can be released and then oxidized in a standard TWC. In addition, this material must be able to deal with high hydrothermal stress, since $\mathrm{HC}$ trap temperature could reach up to $800{ }^{\circ} \mathrm{C}$ and the steam content could be 
up to around $10 \% \mathrm{v} / \mathrm{v}$ of the total gas exhaust. Zeolites are often suggested as HC trap materials due to their stability under a variety of conditions. ${ }^{2,3}$ Different zeolites and zeotipes, with varying pore dimensionality and pore network connectivity, have been studied as adsorbents for HC emission control during the cold start period. Czaplewski et al. ${ }^{4}$ investigated the performance of several zeolites (ZSM-5, MOR, FER, FAU, EUO and Y) as HC traps. Burke et al. ${ }^{5}$ studied BETA zeolite for this application and Elangovan et al. ${ }^{6}$ found that SSZ-33 is a promising material as HC trap. However, none of the reported HC trap materials have demonstrated to achieve the requested characteristics, because it has been found that while heavier exhaust HCs (e.g. aromatics) are adequately trapped, lighter HC components in the exhaust, such as propene, always desorb from the HC trap before the TWC has reached its light-off temperature ${ }^{5}$. In this sense, finding an adsorbent which fulfills this requirement is a priority goal. Previous results obtained in our research group ${ }^{7}$ showed that ZSM-5 (MFI-type framework) could be a promising material as HC trap. It was observed that propene retention under cold start conditions could be improved by cation exchanging in order to create selective adsorption points for light $\mathrm{HC}$ interactions. Thus, molecular simulation studies indicated that ion exchange of ZSM-5 with transition elements, such as copper, could improve the interactions between the zeolite and the propene molecules. ${ }^{8}$ However, the preparation of copper-exchanged zeolites is not a straightforward process since there are several studies in the literature which point out that whilst the majority of copper ions are in the exchangeable positions, as atomically dispersed copper ions, in some cases $\mathrm{CuO}$ species could be present on the outer surface of the zeolite particles, depending on the exchanging process conditions. Experimental evidences are supported by a wide variety of techniques such as TPR- $\mathrm{H}_{2},{ }^{9} \mathrm{UV}-\mathrm{Vis}-\mathrm{NIR}$ DRS, ${ }^{10}$ EPR, ${ }^{11}$ photoluminescence, ${ }^{12}$ XPS and XAES. ${ }^{13}$ These copper oxide species could not only interfere in molecules diffusion into the active sites but also promote the catalytic combustion of HCs. Therefore, both facts could affect the HC trap performance and need to be investigated.

Thus, the aim of this work is to prepare copper-exchanged ZSM-5 zeolites with different ion exchange level and copper loading and to analyze their behaviour as $\mathrm{HC}$ trap under conditions that closely 
simulate the cold start period of a gasoline engine. Copper-exchanged zeolites were selected on the basis of both molecular simulation results ${ }^{8,14}$ and some other studies in which the zeolites stability was guaranteed by the treatment with rare earth metals, such as cerium or lanthanum, ${ }^{5}$ or other elements such as phosphorous, ${ }^{15}$ cooper, ${ }^{16}$ silver $^{17}$ or cobalt. ${ }^{18}$

\section{Experimental}

\subsection{Sample Preparation.}

Commercial NH4-ZSM-5 (ZEOLYST INTERNATIONAL, Si/Al = 15) was converted to H-ZSM-5 by heat treatment in air at $450^{\circ} \mathrm{C}$ for 6 hours, with a heating rate of $5^{\circ} \mathrm{C} / \mathrm{min}$. The $\mathrm{Cu}-\mathrm{ZSM}-5$ samples were prepared by ion exchange of $\mathrm{H}-\mathrm{ZSM}-5$ zeolite, ${ }^{19,20}$ with $\mathrm{Cu}\left(\mathrm{NO}_{3}\right)_{2} \cdot 3 \mathrm{H}_{2} \mathrm{O}$ as $\mathrm{Cu}$ (II) precursor, using a zeolite/solution ratio of $3 \mathrm{~g} / 50 \mathrm{ml}$ and keeping under stirring in a thermostatic bath at $60 \mathrm{rpm}$. Supporting Information Table S1 shows the ion-exchange conditions used. After ion exchange, the samples were filtered and washed with distilled water and then copper-exchanged zeolites were dried at $110{ }^{\circ} \mathrm{C}$ and calcined at $550{ }^{\circ} \mathrm{C}$ for 4 hours, with a heating rate of $1{ }^{\circ} \mathrm{C} / \mathrm{min}$. The samples were denoted as CuH-ZSM5(1), CuH-ZSM-5(2) and CuH-ZSM-5(3).

\subsection{Sample Characterization.}

The samples were characterized by several techniques that are deeply described in the Supporting Information. Briefly, the morphology of the samples was studied by scanning electron microscope (SEM). Copper loading was determined by means of inductively coupled plasma-optical emission spectroscopy (ICP-OES). Solids prepared were also characterized by X-ray diffraction (XRD) for phase identification. The acidity of the samples was examined by $\mathrm{NH}_{3}$-TPD (Temperature-Programmed Desorption) profiles. The results were obtained using a conventional flow-through reactor connected to a thermal conductivity detector (TCD). Details of the experimental procedure can be found in the Supporting Information. The textural characterization of the zeolites was carried out by means of the 
adsorption of $\mathrm{N}_{2}$ at $-196^{\circ} \mathrm{C}$. Surface area was calculated from nitrogen adsorption isotherms using the BET equation $\left(\mathrm{S}_{\mathrm{BET}}\right)$. Total micropore volume $\left(\mathrm{V}_{\mathrm{DR}}\left(\mathrm{N}_{2}\right)\right)$ was calculated applying the DubininRadushkevich (DR) equation to the $\mathrm{N}_{2}$ adsorption data at $-196^{\circ} \mathrm{C}$. The morphology and crystal sizes were examined by transmission electron microscopy (TEM). X-Ray photoelectron spectroscopy (XPS) was used to provide information on how copper was present in the sample. A FTIR spectrometer was used for in-situ DRIFTS adsorption-desorption experiments. Details of the experimental procedure can be found in the Supporting Information. The amount of coke formed during the CST experiments was determined by Thermal Gravimetric Analysis (TGA; TA Instruments, model SDT 2960) for all the samples after being used. More experimental details are given in the Supporting Information

\subsection{Cold Start Tests (CST).}

As it was previously reported by our research group ${ }^{21}$ the experimental conditions for the CST were as follows. The inlet gas composition used for $\mathrm{HC}$ adsorption-desorption experiments was 100 ppmv propene, $90 \mathrm{ppmv}$ toluene, $1 \% \mathrm{v} / \mathrm{v}$ oxygen, $10 \% \mathrm{v} / \mathrm{v}$ water and Ar balance. Steam was generated in an auxiliary reactor with temperature control, and was introduced into the main stream using Ar as carrier gas. All gas flows were fixed using mass flow controllers. The experiments were run in a fixed bed reactor (diameter $=0.457 \mathrm{~cm}$; gas flow $30 \mathrm{ml} / \mathrm{min} ; 0.20 \mathrm{~g}$ of sample) externally heated and coupled to a mass spectrometer Pfeiffer Vacuum (model Omnistar) and with GHSV $=10000 \mathrm{~h}^{-1}$. The following signals were followed: m/z 40 for Argon, 42 for Propene, 91 for Toluene, 32 for Oxygen and 18 for Water. $\mathrm{m} / \mathrm{z} 55$ and 56, related to oligomer formation were also followed during the experiment. It is worth highlighting that only traces of these signals were detected. During the simulated CST, the reactor temperature was increased from $30^{\circ} \mathrm{C}$ to $600{ }^{\circ} \mathrm{C}$ at $50{ }^{\circ} \mathrm{C} / \mathrm{min}$, keeping the maximum temperature for 30 minutes. In order to study the zeolites aging, consecutive CSTs were performed once the reactor temperature was cold down. To study the catalytic behaviour of the samples the evolution of $\mathrm{CO}_{2}$ was studied following $\mathrm{m} / \mathrm{z} 28$ and 44 . 


\section{Results}

\subsection{Sample characterization.}

The samples copper loading was evaluated by means of ICP-OES analysis in order to check that the copper exchanging process was successfully achieved. These data are compiled in Table 1 , showing an increase in the copper content with both the exchanging time and the copper salt concentration. XRD patterns for the ZSM-5 before and after ion-exchange are shown in Figure S1, Supporting Information. All the samples showed peaks at $2 \theta=7.9^{\circ}, 8.9^{\circ}, 23.0^{\circ}, 23.4^{\circ}$ and $23.9^{\circ}$, which corresponded to the specific peaks of ZSM-5 zeolite (MFI structure).$^{22}$ The $\mathrm{Cu}$-exchanged zeolites diffractogram did not show relevant peaks in the region of $2 \theta$ equal to $36^{\circ}$ and $39^{\circ}$, due to $\mathrm{CuO}$ and $\mathrm{Cu}_{2} \mathrm{O}$, respectively, ${ }^{23}$ indicating that $\mathrm{Cu}$ aggregates were not detected by XRD. However, this result was not surprising since XRD evidences could not be detected due to the presence of very tiny CuO crystallites with $\mathrm{d} \leq 4 \mathrm{~nm}$ and/or to a low copper content in the samples. ${ }^{24,25}$

The $\mathrm{NH}_{3}$-TPD profiles of the zeolites prepared in this study are compiled in Figure S2, Supporting Information. In these samples two ammonia desorption peaks were observed, in accordance with previous studies for ZSM-5 zeolites. ${ }^{26,27}$ The first one was found between 120 and $280{ }^{\circ} \mathrm{C}$ and was attributed to desorption of weakly adsorbed ammonia. The high temperature peak was observed in the temperature region between 300 and $500{ }^{\circ} \mathrm{C}$, and was attributed to the ammonia desorption from strong Brönsted acid sites and/or Lewis acid sites. This peak had slightly lower intensity for the CuH-ZSM5(3) zeolite, indicating that a lower amount of strong Brönsted acid sites and/or Lewis acid sites were available and/or accessible in this material. Since almost all the samples showed similar acid properties, a possible effect of the acidity on the different performance of these samples could be ruled out.

Table 1 summarizes the BET surface areas $\left(\mathrm{S}_{\mathrm{BET}}\right)$ and the total micropore $\left(\mathrm{V}_{\mathrm{DR}}\left(\mathrm{N}_{2}\right)\right)$ of $\mathrm{ZSM}-5$ zeolite in acid and ion-exchanged forms. The porosity characterization pointed out that the textural properties of zeolites after the ion exchange steps do not change considerably. 
The presence of $\mathrm{CuO}$ nanoparticles were studied by means of TEM for fresh samples and for some of the solids after three consecutive CSTs. Figure 1 shows TEM images of the parent zeolite H-ZSM-5, and a selection of Cu-containing H-ZSM-5 zeolites. TEM results revealed that H-ZSM-5 and CuHZSM-5(1) (see Figure 1a and 1b) presented the same morphology indicating that the low copper content in this sample was ion-exchanged and atomically distributed. However, black spots were detected in the TEM image of sample CuH-ZSM-5(3) (see Figure 1d), which indicated the presence of $\mathrm{CuO}$ nanoparticles on the outer surface of the ZSM-5 zeolite framework, with particle sizes between 1 and 10 $\mathrm{nm}$. It is worth highlighting that although $\mathrm{CuO}$ nanoparticles were not detected for the fresh CuH-ZSM5(2) sample (see Figure 1c), these $\mathrm{CuO}$ nanoparticles appeared on that sample after being used (see Figure 1f). For this sample, the presence of $\mathrm{CuO}$ in the used sample seemed to point out that $\mathrm{CuO}$ nanoparticles could be formed in the outer surface of the zeolite, which lately acted as seeds for $\mathrm{CuO}$ crystal growing under CST conditions. Interestingly, the presence of $\mathrm{CuO}$ was not detected by $\mathrm{TEM}$ in sample CuH-ZSM-5(1) after being used (see Figure 1e). The formation of these $\mathrm{CuO}$ particles has already been reported in the literature. ${ }^{10}$ Beznis and coworkers prepared ZSM-5 zeolites with different copper content (from 0.9 to $2.6 \mathrm{wt} \%$ ) for the oxidation of methane to methanol. TEM images showed that part of the copper was present as $\mathrm{CuO}$ nanoclusters on the outer surface, which were inactive for methanol production, and only the copper being part of the structure was involved in that reaction.

XPS was used to provide information on how copper is present in the different samples by following the $\mathrm{Cu} 2 \mathrm{p} 3 / 2$ transition. As it can be found in the literature, the binding energy of the $\mathrm{Cu}$ species in the form of $\mathrm{CuO}$ is about $933 \mathrm{eV}$ for $2 \mathrm{p} 3 / 2$ and $953.5 \mathrm{eV}$ for $2 \mathrm{p} 1 / 2$, respectively. ${ }^{28}$ Figure 2 shows the XPS spectra of CuH-ZSM-5(1), CuH-ZSM-5(2) and CuH-ZSM-5(3). According to XPS results, sample CuH-ZSM-5(1) presented a marginal peak, probably due to the fact that copper cations were successfully exchanged and were mostly located inside the particles. Samples CuH-ZSM-5(2) and CuHZSM-5(3) had a peak at around $933 \mathrm{eV}$ which could be attributed to the presence of copper as $\mathrm{CuO}$ with a binding energy of $933.1 \mathrm{eV}$. However, it cannot be totally excluded a small contribution to the 
intensity of this band of the intrazeolitic $\mathrm{Cu}^{+}$with a binding energy of $934.3 .^{29,30}$ On the other hand, XPS spectra of this sample did not show neither peak at $935.4 \mathrm{eV}$, assigned to intrazeolitic $\mathrm{Cu}^{2+}$ species, nor at $935.6 \mathrm{eV}$ assigned to copper in the form of isolated $\mathrm{Cu}^{2+}$. The presence of metallic copper or $\mathrm{Cu}_{2} \mathrm{O}$ cannot be discarded since the characteristic bands of these compounds appeared around 932.2 and $933.1 \mathrm{eV},{ }^{28,31}$ respectively.

\subsection{Cold Start Test (CST).}

Different samples were tested under experimental conditions that mimic the vehicle cold start period. Data are presented in Figure 3 for copper-containing H-ZSM-5 zeolites and Figure S3, Supporting Information for the parent H-ZSM-5 zeolite. During the first minutes of the CST the HC are adsorbed. After some minutes HC signals start to increase because the trap is saturated with $\mathrm{HC}$ and/or the temperature is so high that adsorption is not longer favoured and desorption dominates the process. According to previous results, ${ }^{8,21}$ the results obtained in the CSTs pointed out that H-ZSM-5 did not have a good behaviour as HC trap because the desorption of both model compounds studied took place at low temperatures. Initially, there was a decrease in the propene and toluene concentrations but HC signals soon appeared, first propene, at temperatures around $150{ }^{\circ} \mathrm{C}$ and, later, toluene around $325^{\circ} \mathrm{C}$. The aging effect in H-ZSM-5 zeolite produced a remarkable decrease in the adsorption capacity of the porous solid since desorption peaks of the HCs appeared at lower temperatures in the following cycles (around $75{ }^{\circ} \mathrm{C}$ and $150{ }^{\circ} \mathrm{C}$ for propene and toluene, respectively). As previously reported, ${ }^{21}$ nonstabilized H-ZSM-5 zeolites could suffer for a severe deactivation during operation, likely due to a variation of the $\mathrm{Si} / \mathrm{Al}$ ratio of the zeolites, and thus variations in their hydrophobic and hydrophilic properties, which determine their adsorption and catalytic properties as well as coke formation. In this sense, it should be mentioned that the TGA experiment of the sample H-ZSM-5 revealed that the coke formed during the CST experiments corresponds to $4.5 \mathrm{wt} . \%$, which is in agreement with previous result obtained in our research group. ${ }^{21}$ Finally, it is worth highlighting that final concentration was always 
lower than the corresponding inlet concentration, since $\mathrm{HC}$ catalytic combustion was taking place (see Figure S4, Supporting Information).

CSTs corresponding to Cu-containing ZSM-5 zeolites prepared at different conditions (see Table S1, Supporting Information) are plotted in Figure 3. After 18 hours of exchanging time (sample CuH-ZSM5(1)), see Figure 3(a), it was observed that both propene and toluene remained adsorbed and non HC emissions were detected in any of the three cycles. In these experiments the $\mathrm{CO}_{2}$ concentration was monitored and it was observed that $\mathrm{CO}_{2}$ was only released from $550{ }^{\circ} \mathrm{C}$, indicating that catalytic combustion was taking place at this high temperature (see Figure S4, Supporting Information). This fact pointed out that the remarkable performance of this solid should not be linked to a positive role of the active sites as total oxidation catalyst but to a strong interaction of propene and toluene with the partially copper-exchanged zeolite, which gave the material an excellent performance as HC trap. After that, longer exchanging times were also studied. Surprisingly, in the case of CuH-ZSM-5(2), it was observed that these exchanging conditions led to a solid from which propene was released at very low temperature (about $100{ }^{\circ} \mathrm{C}$ ) and, in addition, some deactivation was observed in the case of toluene retention which was released at lower temperature in the third cycle. As it was shown in the TEM image (see Figure 1(f)), copper nanoparticles were detected on the surface of this solid. This fact pointed out that longer exchanging times were not suitable for this application since some of the exchanged copper was not incorporated in the zeolite structure as extra-framework cations, which seemed to be the active sites for selective adsorption of light HCs in the traps. Then, different exchanging conditions (see Table S1, Supporting Information) were used in order to increase the amount of extra-framework copper cations (sample CuH-ZSM-5(3)). A different performance was observed in the case of this solid. Whilst propene molecules were not released during the CSTs, toluene desorption was observed around $300{ }^{\circ} \mathrm{C}$. In addition, a severe deactivation for toluene adsorption was observed for this material. TGA experiments of the copper containing zeolites after the CST were also performed and the results 
indicated that the coke formed in these samples is slightly lower than in the H-ZSM-5 zeolite $(\sim 3$ wt.\% in all the CuH-ZSM-5 samples) because, as we previously reported, ${ }^{21}$ a higher density of acid sites leads to higher coke content.

\subsection{In-situ DRIFT experiments.}

To understand the interaction between HCs and the different samples and their behaviour as HC trap, insitu DRIFT spectra were recorded during propene adsorption and desorption experiments. Figure 4 shows the DRIFT spectra of CuH-ZSM-5(1) and CuH-ZSM-5(3). Firstly, a blank test was carried out under a helium atmosphere in order to eliminate any possible interference. Then, IR spectra were recorded at different times (from 2 to 60 minutes, when the zeolite breakthrough time was reached) during propene adsorption at room temperature.

Regarding the different features observed in the samples before propene adsorption (see Figures A (a) a and $\mathrm{B}$ (a) a), a peak in the $\mathrm{O}-\mathrm{H}$ stretching region and centered at $3740 \mathrm{~cm}^{-1}$ could be observed for both samples. This peak corresponded to the $v(\mathrm{OH})$ stretching of free silanols mainly located on the external surface $^{32}$. In sample CuH-ZSM-5(3) a second band at $3600 \mathrm{~cm}^{-1}$ appeared, which could be due to the $v$ $(\mathrm{OH})$ of strongly acidic $\mathrm{Si}(\mathrm{OH}) \mathrm{Al}$ Brønsted groups present inside the channels ${ }^{32,33,34}$. In the case of CuH-ZSM-5(1), this peak had lower intensity, indicating the presence of a smaller number of strongly acidic $\mathrm{Si}(\mathrm{OH}) \mathrm{Al}$ Brønsted groups in the zeolite structure. This band at $3600 \mathrm{~cm}^{-1}$ was also observed in the ZSM-5 acid form (spectrum not shown here).

Related to the spectra recorded during propene adsorption, the most relevant spectroscopic features observed after interaction with propene were as follows: ${ }^{32}$ (a) the band associated with the external silanols $\left(3740 \mathrm{~cm}^{-1}\right)$ was left nearly unperturbed; (b) the band due to the strong Brønsted sites $\left(3600 \mathrm{~cm}^{-}\right.$ 1) disappeared; (c) a broad and low intensity band at $3550 \mathrm{~cm}^{-1}$, due to the formation of hydrogen bonded complexes involving unreacted Brønsted sites and oligomeric chains was formed; and (d) bands due to both $v\left(\mathrm{CH}_{3}\right)\left(2950 \mathrm{~cm}^{-1}\right)$ and $v\left(\mathrm{CH}_{2}\right)\left(2870 \mathrm{~cm}^{-1}\right)$, which were attributed to oligomers entrapped 
in the zeolitic channel appeared simultaneously.

In both samples, CuH-ZSM-5(1) and CuH-ZSM-5(3), the intensity and width of the peaks remained almost unchanged when increasing the adsorption time, which suggests that there were no changes in the interaction of the propene molecules with the zeolite surface during the adsorption.

In addition, to test the strength of the interaction between propene and the different samples, spectra during propene desorption were recorded. To desorb propene, samples were heated up to $350{ }^{\circ} \mathrm{C}$ under an helium flow and the IR spectra were recorded every $25^{\circ} \mathrm{C}$. A similar behaviour was observed for both samples. Figures $4 \mathrm{~A}(\mathrm{~b})$ and $4 \mathrm{~B}(\mathrm{~b})$ show the DRIFT spectra during propene desorption in $\mathrm{CuH}-$ ZSM-5(1) and CuH-ZSM-5(3) samples, respectively, at different temperatures (50, 150, 250 and 350 ${ }^{\circ} \mathrm{C}$ ) and the blank spectrum obtained in helium atmosphere. It can be observed that the characteristic band of the interaction between zeolite and propene did not disappear completely after heating the samples at $350{ }^{\circ} \mathrm{C}$ and a broad band due to the vibration of $\mathrm{CH}_{2}$ and $\mathrm{CH}_{3}$ species remained, indicating that propene was retained in the zeolites even at high temperatures. This fact was in agreement with CST data.

\section{Discussion}

In a previous published work, ${ }^{8}$ molecular simulation data showed that partially-exchanged copper zeolites could be very promising $\mathrm{HC}$ traps when propene, toluene and water molecules were used in the simulations as model compounds. It was observed that when both copper and protons were present in the ZSM-5 structure, multiple selective adsorption sites were created and most interestingly, free adsorption sites were available for the retention of light HCs. Briefly, water molecules tended to locate at those intersections close to the copper cations while propene molecules tended to locate through the straight and sinusoidal channels where copper was not present. In addition, toluene was more likely located at those intersections where copper was not in the proximity. Thus, it was designed a solid where the copper cations strongly attracted water molecules leaving the rest of the adsorption sites for 
the other molecules in the exhaust, which minimized the competitive adsorption of gases. Another possible positive aspect of this solid was that the presence of some intersections free of water molecules could facilitate the pathway of the different $\mathrm{HCs}$ to the inner zeolite active sites. Against this background, different results were found in the case of the parent H-ZSM-5 zeolite where water tended to locate in all the channel intersections thus likely blocking the diffusion of $\mathrm{HC}$ molecules to inner adsorption sites, ${ }^{8}$ which could explain the poor performance of this solid under cold start conditions. ${ }^{8}$

Now, these findings seem to be in accordance with the experimental results obtained for partially copper-exchanged zeolites in this work, since it was observed that an optimum partially copperexchanged zeolite could behave as an ideal trap under simulated cold start conditions. Thus, it was demonstrated that the amount of copper as extraframework cation and the presence of $\mathrm{CuO}$ surface nanoparticles were both key parameters determining the performance of these solids as HC traps. This fact highlighted the paramount importance of the exchanging process conditions. In this sense, solid exchanged for 18 hours (sample CuH-ZSM-5(1)) had a good performance in HC abatement. This exceptional behaviour for propene adsorption was confirmed by in-situ DRIFTS since it was found that HC molecules were strongly retained and remained inside the porosity even after thermal desorption at $350{ }^{\circ} \mathrm{C}$. Accordingly, evolved $\mathrm{CO}_{2}$ for this solid was only detected at higher temperature, $550{ }^{\circ} \mathrm{C}$, due to combustion of the adsorbed HCs before they were released during heating. This fact pointed out that the HC desorption in this solid was delayed up to, at least, $550{ }^{\circ} \mathrm{C}$, which was a very remarkable result. Longer exchanging times were also studied, (sample CuH-ZSM-5(2)). Surprisingly, it was found that a longer exchanging time led to an unsuitable solid as HC trap. For this material, not only propene was released at low temperature (below TWC requirements) but also trap deactivation was observed for toluene abatement. According to XPS results, it could be observed that the formation of $\mathrm{CuO}$ nanoparticles on the zeolite surface instead of proton exchanging seemed to be preferred at longer exchanging times, decreasing the amount of copper species present as extraframework cations. In addition, TEM results of the used samples showed that these $\mathrm{CuO}$ nanoparticles tended to sinter during 
the reaction test since $\mathrm{CuO}$ nanoparticles were clearly detected in the surface of this sample (see Figure 1f). These facts could explain the poor performance of this solid as HC trap since the amount of exchanged copper seemed to be very low and, in addition, $\mathrm{CuO}$ nanoparticles could be partially blocking the access to the inner microporosity of the zeolite. Sintering and growing of $\mathrm{CuO}$ surface nanoparticles could also explain the deactivation process observed in the case of toluene retention, since toluene molecular size is higher than propene and, therefore, steric constrains were more sensible to this molecule.

Finally, different exchanging conditions were selected in order to increase the amount of exchanged copper, (sample CuH-ZSM-5(3)). An exceptional propene retention capacity was observed for this zeolite. However, toluene retention capacity was initially superior (over TWC requirements) but decreased during cyclic operation. According to ICP-OES data, the total amount of copper in this sample was much higher than the amount found in the other samples. Thus, although $\mathrm{CuO}$ nanoparticles were clearly detected by TEM and XPS, exchanged copper was likely higher than that for CuH-ZSM5(2), leading to a good performance for light $\mathrm{HC}$ abatement. Unfortunately, this HC trap was not suitable for the abatement of heavy HCs. Again, this could be related to the fact that $\mathrm{CuO}$ nanoparticles were sintering in the outer ZSM-5 zeolite surface during cyclic operation, and this could result in a zeolite deactivation as toluene trap, due to the higher molecule size of toluene compared with that of propene.

The obtained results revealed that the partial substitution of extra-framework protons by copper cations made CuH-ZSM-5 ideal materials as HC traps. Results of HC CSTs pointed out that copper loading and location played an important role in the behaviour of copper ion exchanged ZSM-5 zeolites as HC trap. Among all the zeolites studied, CuH-ZSM-5(1) was the zeolite that showed the best performance both in terms of HC trap efficiency and the stability against aging after several CST cycles. Thus, the fact that the copper was ion-exchanged in the zeolite seemed to play an important role against aging, while a deactivation was observed for the other samples due to the sintering of $\mathrm{CuO}$ nanoparticles on the outer 
zeolite surface. However, a higher number of cycles under real conditions should be performed in order to ensure the stability of the sample and the exceptional HC removal efficiency observed for this solid.

\section{AUTHOR INFORMATION}

\section{Corresponding Author}

* Phone: +34 965903 966; Fax: + 965903 454; E-mail: d.lozano@ua.es

\section{ACKNOWLEDGMENTS}

The authors thank Spanish Ministerio de Medio Ambiente y Medio Rural y Marino (Project 331/PC08/3-13.1), as well as Spanish Ministerio de Economía y Competitividad (Projects CTQ200910813/PPQ and CTQ2012/31762) and Generalitat Valenciana (PROMETEO/2009/047) for financial support. M. Navlani-García thanks University of Alicante for the PhD fellowship and B. Puértolas thanks the Ministry of Education of Spain for FPU grant (FPU grant AP2009-3544).

\section{ASSOCIATED CONTENT}

\section{Supporting Information}

Additional information on experimental details about H-ZSM-5 and CuH-ZSM-5 synthesis and characterization. XRD patterns, TPD-NH 3 results, CSTs of H-ZSM-5 zeolite, $\mathrm{CO}_{2}$ evolution during the CSTs for the different zeolites. This information is available free of charge via the Internet at http://pubs.acs.org. 


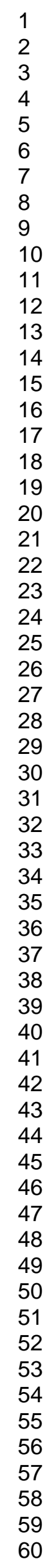

FIGURE CAPTIONS 


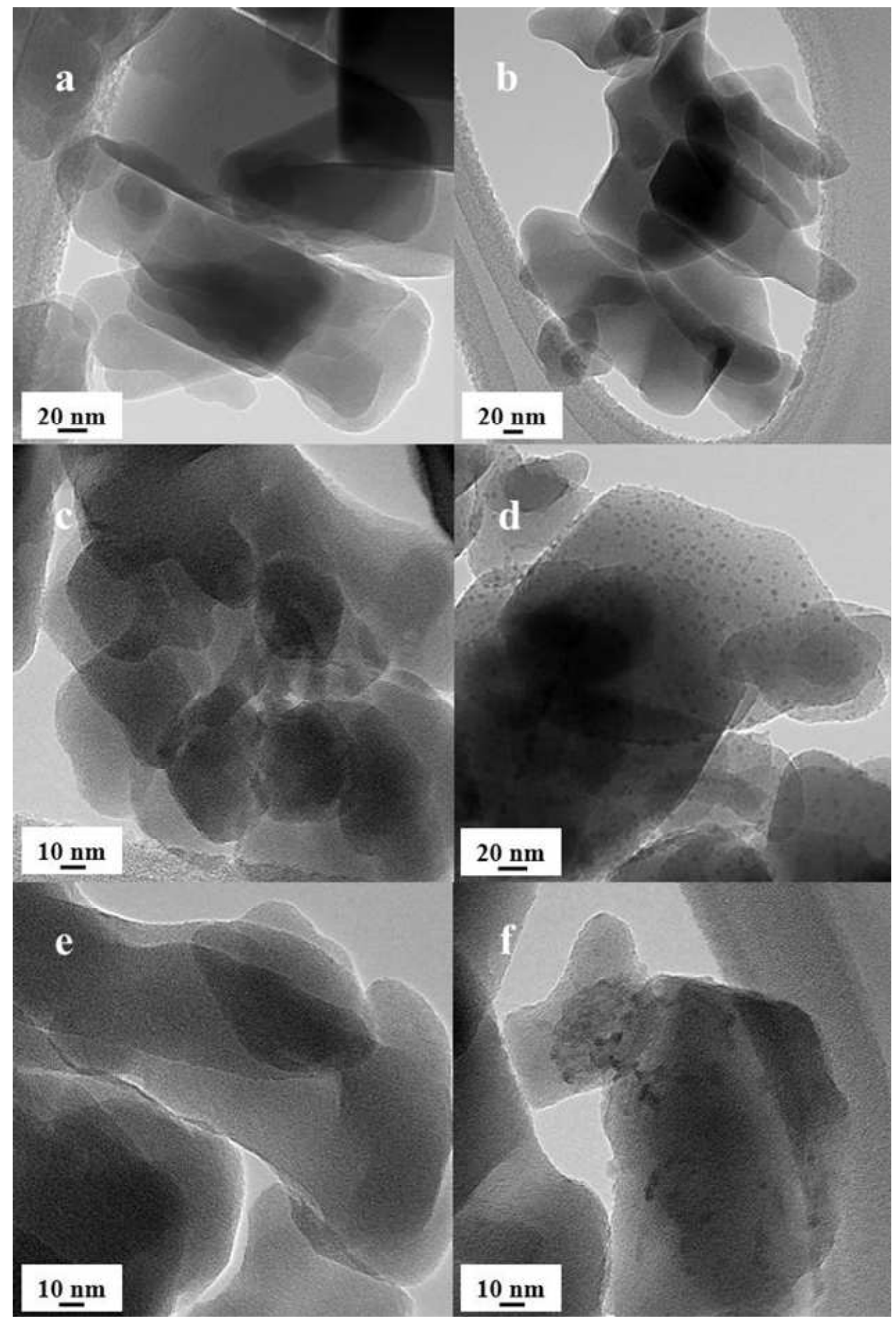

Figure 1. TEM images of (a) H-ZSM-5, (b) CuH-ZSM-5(1), (c) CuH-ZSM-5(2), (d) CuH-ZSM-5(3), (e) CuH-ZSM-5(1) used, (f) CuH-ZSM-5(2) used. 


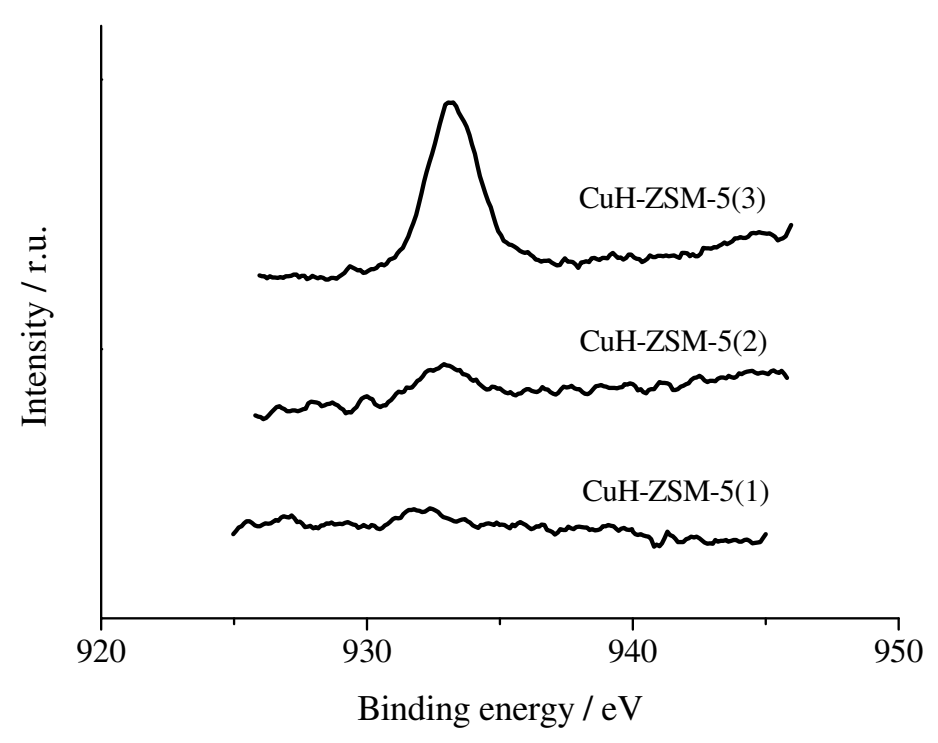

Figure 2. $\mathrm{Cu}$ 2p3/2 core level spectra on CuH-ZSM-5 zeolites. 
(a)

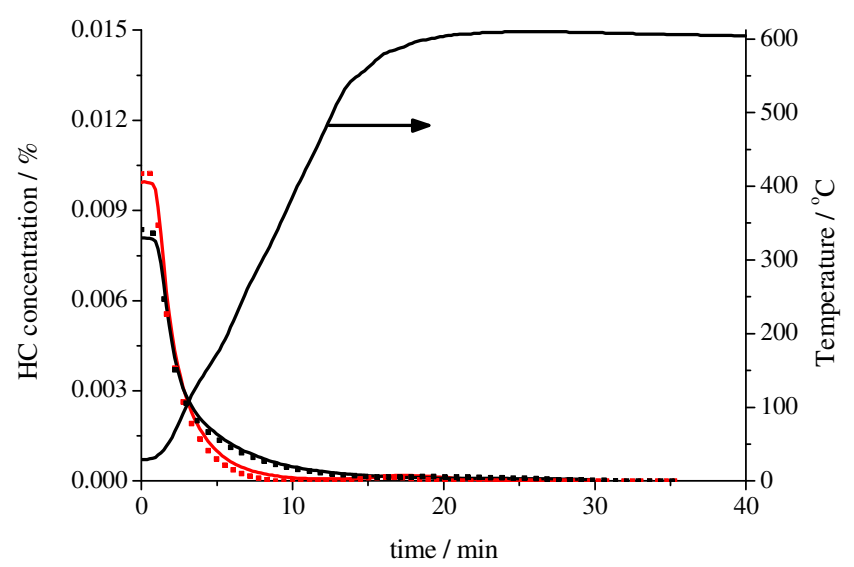

(b)

(c)
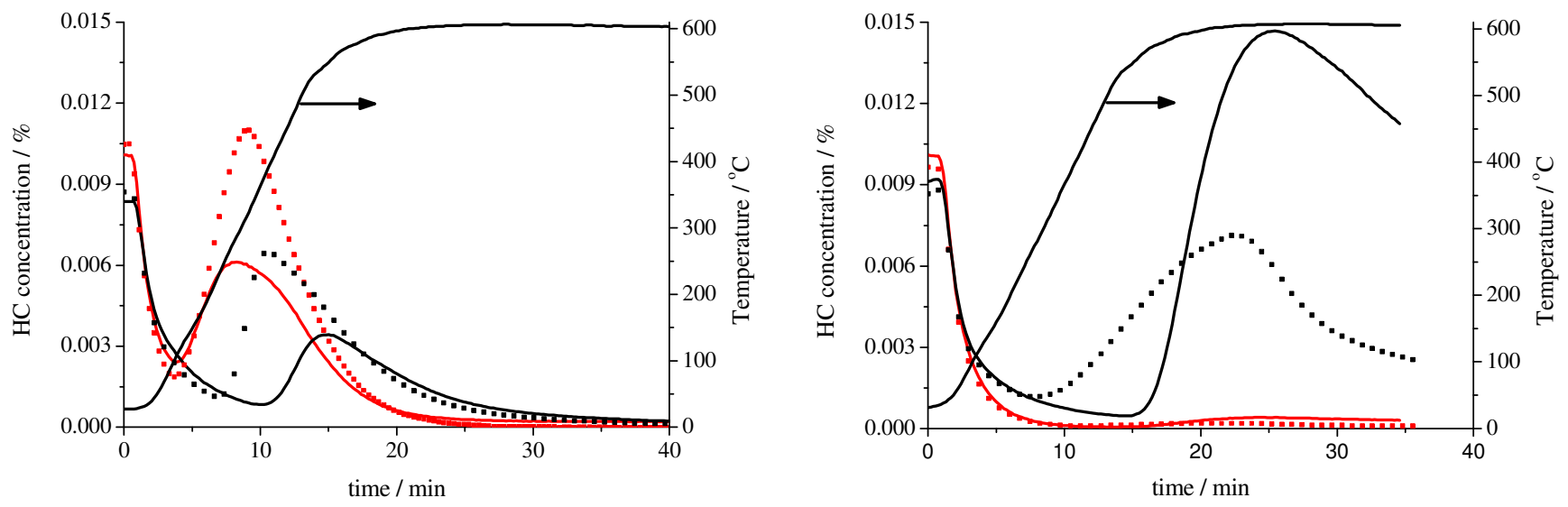

Figure 3. CSTs performed with Cu-containing ZSM-5 zeolites: (a) CuH-ZSM-5(1), (b) CuH-ZSM-5(2) and (c) $\mathrm{CuH}-\mathrm{ZSM}-5(3)$. Conditions: $100 \mathrm{ppmv}$ propene, $90 \mathrm{ppmv}$ toluene, $1 \% \mathrm{v} / \mathrm{v} \mathrm{O}_{2}, 10 \%$ v/v $\mathrm{H}_{2} \mathrm{O}$ and Ar balance. GHSV $=10000 \mathrm{~h}^{-1}$. Red lines represent propene concentration profiles and black lines represent toluene. Straight lines represent the first cycle and dotted lines represent the third cycle. 
A.

(a) (b)
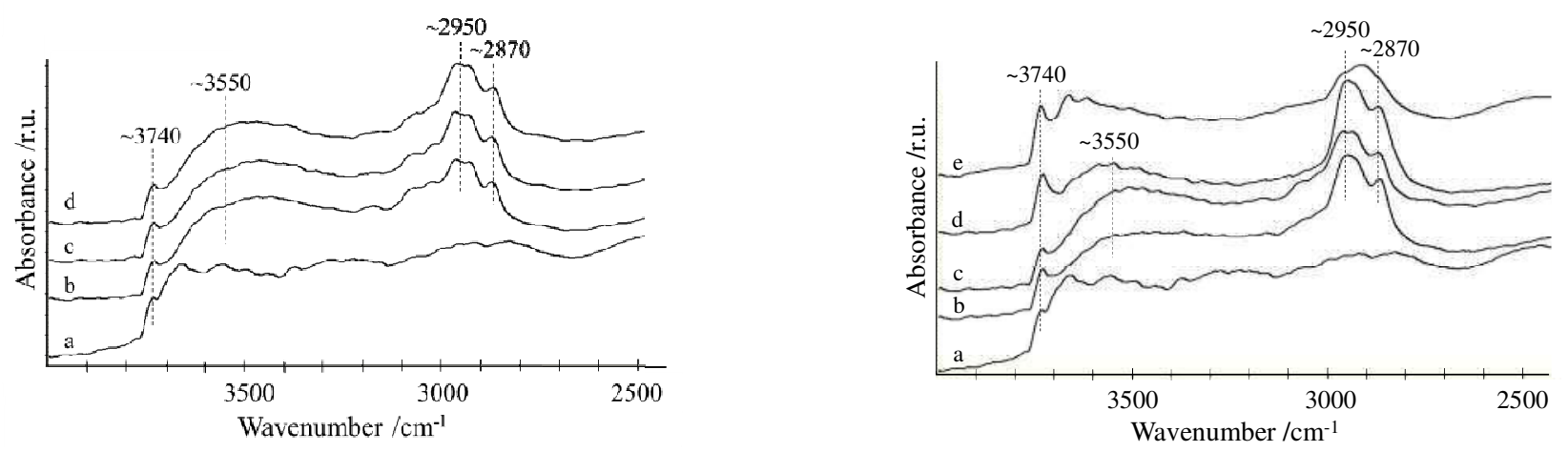

B.

(a)

(b)
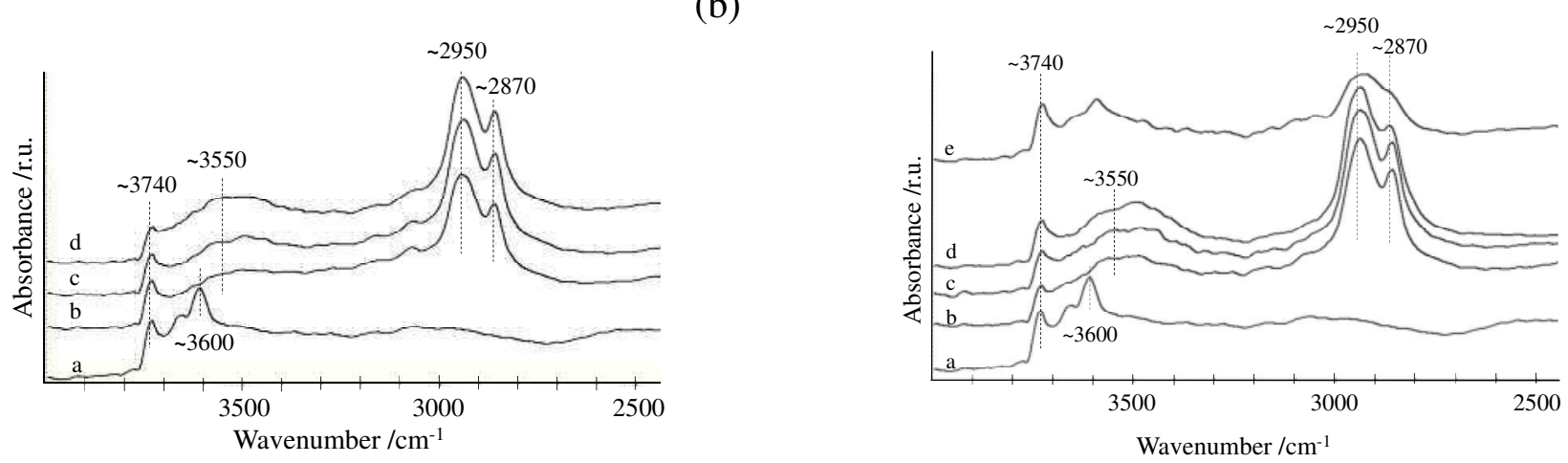

Figure 4. DRIFT spectra of samples: A: CuH-ZSM-5(1), and B: CuH-ZSM-5(3), during propene adsorption and desorption experiments: (a) during propene adsorption at different adsorption times: a: in helium atmosphere, b: after 2 minutes, c: after 10 minutes, d: after 60 minutes; (b) during propene desorption experiment at different temperatures: a: in helium atmosphere, b: at a temperature of $50{ }^{\circ} \mathrm{C}$, c: at $150^{\circ} \mathrm{C}$, d: at $250^{\circ} \mathrm{C}$, e: at $350^{\circ} \mathrm{C}$. 


\section{TABLES.}

Table 1. $\mathrm{Cu}$ content by ICP-OES analysis and porous texture characterization results.

\begin{tabular}{cccc}
\hline Sample & $\begin{array}{c}\text { Cu content } \\
\text { (wt.\% })\end{array}$ & $\begin{array}{c}\mathrm{S}_{\mathrm{BET}}\left(\mathrm{N}_{2}\right) \\
\left(\mathrm{m}^{2} / \mathrm{g}\right)\end{array}$ & $\begin{array}{c}\mathrm{V}_{\mathrm{DR}}\left(\mathrm{N}_{2}\right) \\
\left(\mathrm{cm}^{3} / \mathrm{g}\right)\end{array}$ \\
H-ZSM-5 & - & 371 & 0.16 \\
CuH-ZSM-5(1) & 0.17 & 400 & 0.18 \\
CuH-ZSM-5(2) & 0.20 & 381 & 0.17 \\
CuH-ZSM-5(3) & 1.12 & 391 & 0.17 \\
\hline
\end{tabular}




\section{REFERENCES}

(1) Navarro, M.V.; Puértolas, B.; García, T.; Murillo, R.; Mastral, A.M.; Varela-Gandía, F.J.; Lozano-Castelló, D.; Cazorla-Amorós, D.; Bueno-López, A. Experimental and simulated propene isotherms on porous solids. Appl. Surf. Sci. 2010, 256, 5292-5297.

(2) Lafyatis, D.S.; Ansell, G.P.; Bennett, S.C.; Frost, J.C.; Millington, P.J.; Rajaram, R.R.; Walker, A.P.; Ballinger, T.H. Ambient temperature light-off for automobile emission control. Appl. Catal., B 1998, 18, 123-135.

(3) Iliyas, A.; Zahedi-Niaki, M.H.; Eić, M.; Kaliaguine, S. Control of hydrocarbon cold-start emissions: A search for potential adsorbents. Microporous Mesoporous Mater. 2007, 102, 171-177.

(4) Czaplewski, K.F.; Reitz, T.L.; Kim, Y.J.; Snurr, R.Q. One-dimensional zeolites as hydrocarbon traps. Microporous Mesoporous Mater. 2002, 56, 55-64.

(5) Burke, N.R.; Trimm, D.L.; Howe, R.F. The effect of silica:alumina ratio and hydrothermal ageing on the adsorption characteristics of BEA zeolites for cold start emissions control. Appl. Catal., B 2003, 46, 97-104.

(6) Elangovan, S.P.; Ogura, M.; Davis, M.E.; Okubo, T. J. SSZ-33: a promising material for use as a hydrocarbon trap. Phys. Chem. B 2004, 108, 13059-13061.

(7) López, J.M.; Navarro, M.V.; García, T.; Murillo, R.; Mastral, A.M.; Varela-Gandía, F.J.; Lozano-Castelló, D.; Bueno-López, A.; Cazorla-Amorós, D. Screening of different zeolites and silicoaluminophosphates for the retention of propene under cold start conditions. Microporous Mesoporous Mater. 2010, 130, 239-247.

(8) Puértolas, B.; Navlani-García, M.; López, J.M.; García, T.; Murillo, R.; Mastral, A.M.; Navarro, M.V.; Lozano-Castelló, D.; Bueno-López, A.; Cazorla-Amorós, D. Molecular simulation design of a 
multisite solid for the abatement of cold start emissions. Chem. Commun., 2012, 48, 6571-6573

(9) Sárkány, J.; d'Itri, J.L.; Sachtler, W.M.H. Redox chemistry in excessively ion exchange Cu/NaZSM-5. Catal. Lett. 1992, 16, 241-249.

(10) Beznis, N. V.; Weckhuysen, B.M.; Bitter, J.H. Cu-ZSM-5 zeolites for the formation of methanol from methane and oxygen: probing the active sites and spectator species. Catal. Lett. 2010, 138, 1422.

(11) Larsen, S.C.; Aylor, A.; Bell, A.T.; Reimer, J.A. Electron paramagnetic resonance studies on copper ion-exchanged ZSM-5. J. Phys. Chem. 1994, 98, 11533-11540.

(12) Dědeček, J.; Wichterlová, B. Sitting and redox behaviour of Cu ions in CuH-ZSM-5 zeolites. $\mathrm{Cu}^{+}$photoluminiscence study. J. Phys. Chem. 1994, 98, 5721-5727.

(13) Shpiro, E.S.; Grünert, W.; Joyner, R. W.; Baeva, G.N. Nature, distribution and reactivity of copper species in over-exchanged Cu-ZSM-5 catalysts: an XPS/XAES study. Catal. Lett. 1994, 24, 159-169.

(14) Navarro, M.V.; Et al. Computer assisted design of porous solids for voc's emission control by adsorption in vehicle cold start. In Characterisation of Porous Solids VIII; Kaskel, S., Llewellyn, P., Rodriguez-Reinoso, F., Seaton N.A., Eds.; RSC Publishing: Cambridge 2009; pp 271.

(15) Yang, G.; Zhuang, J.; Wang, Y.; Zhou, D.; Yang, M.; Liu, X.; Han, X.; Bao, X. Enhancement on the hydrothermal stability of ZSM-5 zeolites by the cooperation effect of exchanged lanthanum and phosphoric species. J. Mol. Struct. 2005, 737, 271-276.

(16) Grinsted, R. A.; Jen, H. W.; Montreuil, C. N.; Rokosz, M. J.; Shelef, M. The relation between deactivation of Cu-ZSM-5 in the selective reduction of NO and dealumination of the zeolite. Zeolites 
1993, 13, 602-606.

(17) He, X.; Huang, X.; Wang, Z.; Yan, Y. The role of silver species on the hydrothermal stability of zeolite catalysts. Microporous Mesoporous Mater. 2011, 142, 398-403.

(18) Armor, J. N.; Farris, T. S. The unusual hydrothermal stability of Co-ZSM-5, Appl. Catal., B. 1994, 4, L11-L17.

(19) Nieminen, V.; Kumar, N.; Datka, J.; Päivärinta, J.; Hotokka, M.; Laine, E.; Salmi, T.; Murzin, D.Y. Active copper species in 1-butene skeletal isomerization: comparison between copper-modified MCM-41 and beta catalysts. Microporous Mesoporous Mater. 2003, 60, 159-171.

(20) Komvokis, V.G.; Iliopoulou, E.F.; Vasalos, I.A.; Triantafyllidis, K.S.; Marshall, C.L.; Development of optimized Cu-ZSM-5 deNO ${ }_{x}$ catalytic materials both for HC-SCR applications and as FCC catalytic additives. Appl. Catal. A: Gen. 2007, 325, 345-352.

(21) Puértolas, B. ; López, J.M. ; Navarro, M.V. ; García, T. ; R. Murillo, R. ; Mastral, A. M. ; Varela-Gandía, F.J. ; Lozano-Castelló, D. ; Bueno-López, A. ; Cazorla-Amorós, D. Abatement of hydrocarbons by acid BETA and ZSM-5 zeolites under cold-start conditions. Adsorption. 2013; DOI $10.1007 / \mathrm{s} 10450-012-9458-3$.

(22) International zeolite association website; http://www.iza-online.org/.

(23) Kharas, K.C.C.; Robota, H.J.; Liu, D.J. Deactivation in Cu-ZSM-5 lean-burn catalysts. Appl. Catal. B. 1993, 2, 225-237.

(24) Yan, J.Y.; Lei, G.-D.; Sachtler, W.M.H.; Kung, H. H. Deactivation of Cu/ZSM-5 catalysts for lean $\mathrm{NO}_{\mathrm{x}}$ reduction: characterization of changes of $\mathrm{Cu}$ state and zeolite support. J. Catal. 1996, 161, 43-54. 
(25) Urquieta-González, E.A.; Martins, L.; Peguin, R.P.S.; Batista, M.S. Identification of extraframework species on Fe/ZSM-5 and Cu/ZSM-5 catalysts typical microporous molecular sieves with zeolitic structure. Mater. Res. 2002, 5(3), 321-327.

(26) Katada, N.; Igi, H.; Kim, J.H.; Niwa, M. Determination of the acidic properties of zeolite by theoretical analysis of temperature-programmed desorption of ammonia based on adsorption equilibrium. J. Phys. Chem. B. 1997, 110, 5969-5997.

(27) Lónyi, F.; Valyon, J. On the interpretation of the $\mathrm{NH}_{3}-\mathrm{TPD}$ patterns of H-ZSM-5 and $\mathrm{H}-$ mordenite. Microporous Mesoporous Mater. 2001, 47, 293-301.

(28) M'Ramadj, O.; Zhang, B.; Li, D.; Wang, X.; Lu, G. Catalytic combustion of methane over high copper-loading ZSM-5 catalysts. J. Nat. Gas Chem. 2007, 16, 258-265.

(29) Landong, L.I.; Jixin, C.; Shujuan, Z.; Gfuxiang, Z.; Naijia, G.; Tianyou, W.; Shuliang, L. Selective catalytic reduction of nitrogen oxides from exhaust of lean burn engine over in-situ synthesized Cu-ZSM-5/cordierite. Environ. Sci. Technol. 2005, 39, 2841-2847.

(30) Dossi, C.; Fusi, A.; Moretti, G.; Recchia, S.; Psaro, R. On the role of carbonaceous material in the reduction of $\mathrm{Cu}^{2+}$ to $\mathrm{Cu}^{+}$in $\mathrm{Cu}-Z \mathrm{ZSM}-5$ catalysts. Appl. Catal., A. 1999, 188, 107-119.

(31) López-Suárez, F. E.; Bueno-López, A.; Illán-Gómez, M.J.; Adamski, A.; Ura, B.; Trawczynski, J. Copper catalyst for soot oxidation: alumina versus perovskite supports. Environ. Sci. Technol. 2008, 42, 7670-7675.

(32) Bordiga, S.; Civalleri, B.; Spoto, G.; Pazè, C.; Lamberti, C.; Ugliengo, P.; Zecchina, A. Repulsive and attractive interactions between Brønsted sites and hydrocarbon species with partial carbocationic character in restricted spaces: comparison of IR results and ab initio calculations. $J$. Chem. Soc., Faraday Trans. 1997, 93, 1893-3898. 
(33) Wang, X.; Chen, H.; Sachtler, W.M.H. Selective reduction of NOx with hydrocarbons over Co/MFI prepared by sublimation of $\mathrm{CoBr}_{2}$ and other methods. Appl. Catal., B. 2001, 29, 47-60.

(34) Lónyi, F.; Solt, H.E.; Valyon, J.; Boix, A.; Gutierrez, L.B.; The SCR of NO with methane over In, H- and Co, In, H-ZSM-5 catalysts: The promotional effect of cobalt. Appl. Catal., B. 2012, 117$118,212-223$. 